\title{
Spawning pattern and type of fecundity in relation to ovarian allometry in the round herring Etrumeus teres
}

\author{
Guido Plaza $\cdot$ Hideo Sakaji $\cdot$ Hitoshi Honda \\ Yuichi Hirota $\cdot$ Kazuya Nashida
}

Published online: 10 January 2008

(C) Springer-Verlag 2007

\section{Erratum to: Mar Biol (2007) 152:1051-1064 \\ DOI 10.1007/s00227-007-0756-3}

Unfortunately, some of the authors' affiliations were incorrect and the legend to Fig. 3 did not correspond to the color version. The correct affiliations as well as the correct legend to Fig. 3 are given below.
Affiliations
G. Plaza (州)
Escuela de Ciencias del Mar, Facultad de Recursos Naturales, Pontificia Universidad Católica de Valparaíso, Avenida Altamirano 1480, Valparaíso, Chile

H. Sakaji

National Research Institute of Fisheries Science (NRIFS), Fisheries Research Agency (FRA), 2-14-4 Fukuura, Kanazawa, Yokohama, Kanagawa 236-8648, Japan

Y. Hirota $\cdot$ K. Nashida

NRIFS, FRA, Kochi Kuroshio Research Laboratory, Sanbashi-dori 6-1-21, Kochi 780-8010, Japan

H. Honda

Tropical Tuna Resources Division, National Research Institute of Far Seas Fisheries, FRA, 5-7-1 Orido, Shimizu, Shizuoka 424-8633, Japan

Legend to Fig. 3

The online version of the original article can be found under doi:10.1007/s00227-007-0756-3.

G. Plaza $(\bowtie)$

Escuela de Ciencias del Mar,

Facultad de Recursos Naturales,

Pontificia Universidad Católica de Valparaíso,

Avenida Altamirano 1480, Valparaíso, Chile

e-mail: guido.plaza@ucv.cl

H. Sakaji

National Research Institute of Fisheries Science (NRIFS),

Fisheries Research Agency (FRA), 2-14-4 Fukuura,

Kanazawa, Yokohama, Kanagawa 236-8648, Japan

Y. Hirota $\cdot$ K. Nashida

Kochi Kuroshio Research Laboratory, NRIFS,

FRA, Sanbashi-dori 6-1-21, Kochi 780-8010, Japan

H. Honda

Tropical Tuna Resources Division,

National Research Institute of Far Seas Fisheries,

FRA, 5-7-1 Orido, Shimizu, Shizuoka 424-8633, Japan 
Fig. 3 Etrumeus teres. a Modal progression (MP) of the frequency distribution of intraovarian oocytes sorted by the mean diameter of the most advanced mode of oocytes (MODAM) in 60 females collected in January 2004. Dark green areas ovaries with $\mathrm{Py}$ oocytes; yellowish areas ovaries with Ay; sky blue areas hydrated ovaries. b Oocyte size frequency distribution in a maturing fish. Brown bars denote oogonia and oocytes in primary and secondary growth phase smaller than $0.15 \mathrm{~mm}$ that were excluded from MP analyses.

Dark green bars denote cortical alveoli oocytes and yellow bars yolked oocytes. $\mathbf{c}$ MP analysis in 30 mature females collected in June 2003, a month close to the resting period. $Y$-axes were not drawn in MP graphs to make them easier to understand

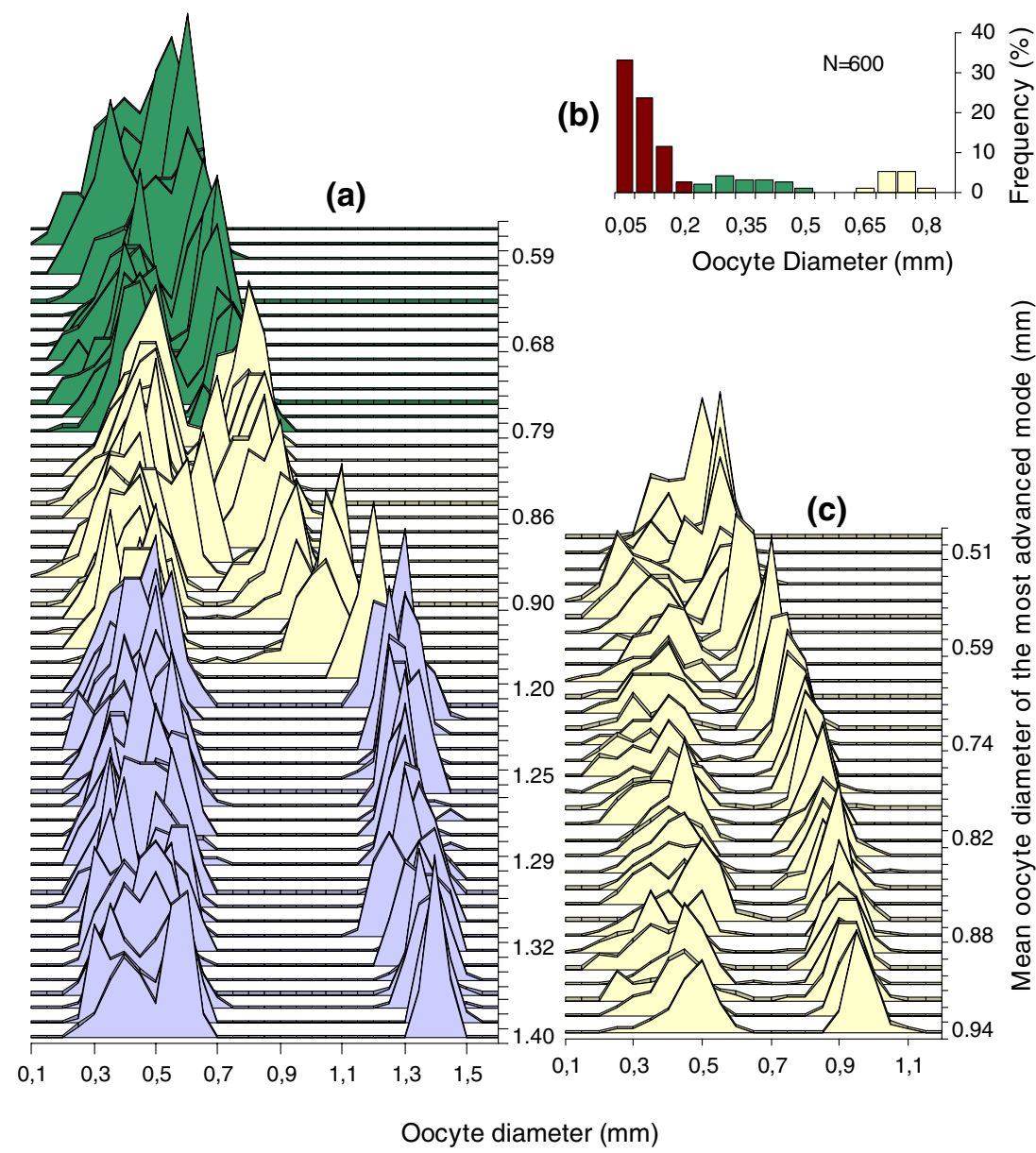

